\title{
Aprotinin improves myocardial recovery after ischemia and reperfusion
}

\author{
Effects of the drug on isolated rat hearts
}

The effects of aprotinin, a protease inhibitor, on the ischemic and nonischemic isolated rat heart was investigated with the use of the modified Langendorff model. During phase $I$ of the study, hearts were perfused with either low-dose aprotinin $\left(10^{5} \mathrm{KIU} / \mathrm{L}\right)$, high-dose aprotinin $\left(10^{6} \mathrm{KIU} / \mathrm{L}\right)$, or normal saline solution added to modified Krebs-Henseleit solution. No statistically significant differences in contraction amplitude, contractility, coronary flow, and wet/dry heart weight ratio were observed among the three groups of hearts. In phase II, hearts were exposed to a 40 -minute period of global ischemia at $31^{\circ} \mathrm{C}$. Ischemic arrest was induced by warm cardioplegia. Before ischemia and during cardioplegia, hearts were perfused with either aprotinin $10^{6} \mathrm{KIU} / \mathrm{L}(n=10)$ or normal saline solution $(n=10)$ for 30 minutes. On reperfusion, recovery of hearts treated with aprotinin was significantly better than that of control hearts, as reflected by better contractility (analysis of variance, $p=0.011$ ), higher coronary flow $(p<0.025)$, and lower creatine kinase levels $(p<0.05)$. No statistically significant differences in contraction amplitude were observed between the two groups. When the effect of ischemia within each group of hearts was analyzed, the preserving effect of aprotinin was even more pronounced. In the control group, ischemia caused a decrease in contractility $(p<0.025)$ and a decrease in oxygen consumption $(p=0.006)$; by contrast, in the aprotinin group the preischemic values were maintained. Accordingly, we conclude that aprotinin at concentrations up to $10^{6} \mathrm{KIU} / \mathrm{L}$ has no deleterious effect on normally perfused hearts and has a significant protective effect on the ischemic heart when used in high doses in the preischemic period. (J THORAC CaRdiovasC SuRg 1994;108:10918)

Jacob Gurevitch, MD, Jaacov Barak, MD, Edith Hochhauser, PhD, Yosef Paz, MD, and Vladimir Yakirevich, MD, Tel-Aviv, Israel

$T_{\text {he }}$ he rapid biochemical, functional, and structural changes that occur in the heart during early ischemia and reperfusion have been fully described. ${ }^{1-4}$ Three major events link metabolic changes and structural damage: (1) oxidative damage caused by free radicals (oxygen paradox) ${ }^{5-7}$ (2) uncontrolled ionic influx (calcium paradox) ${ }^{7-9}$ and (3) release of lysosomal hydrolases (proteases, lipases, and glycosidases). ${ }^{10-14}$ The first two occur primarily during reperfusion and are a part of reperfusion injury phenomenon, but the release of lysos-

From the Department of Thoracic and Cardiovascular Surgery, TelAviv-Elias Sourasky Medical Center, Tel-Aviv University, TelAviv, Israel.

Received for publication Dec. 12, 1992.

Accepted for publication Sept. 27, 1993.

Copyright $\odot 1994$ by Mosby-Year Book, Inc.

$0022-5223 / 94 \$ 3.00+0 \quad \mathbf{1 2 / 1 / 5 2 0 6 6}$ omal enzymes occurs in the heart during early and late ischemia. $1,2,10-14$

In recent years, aprotinin (a naturally occurring protease inhibitor) has been routinely given in many institutions in patients undergoing cardiac operations, particularly those with an increased risk of blood loss. The effect of the drug on perioperative blood loss in cardiac surgery is established. ${ }^{15-17}$ However, despite the wide use of aprotinin, the effect of the drug on myocardial performance of normally perfused hearts is yet unknown.

Because proteolytic enzymes play an important role in ischemic myocardial damage, one may expect a protective effect of aprotinin on the ischemic heart. This hypothesis was recently tested in animal studies: Aprotinin was shown to depress the release and the effect of myocardial lysosomal enzymes and to preserve tissue adenosine triphosphate, other adenine nucleotides, and 


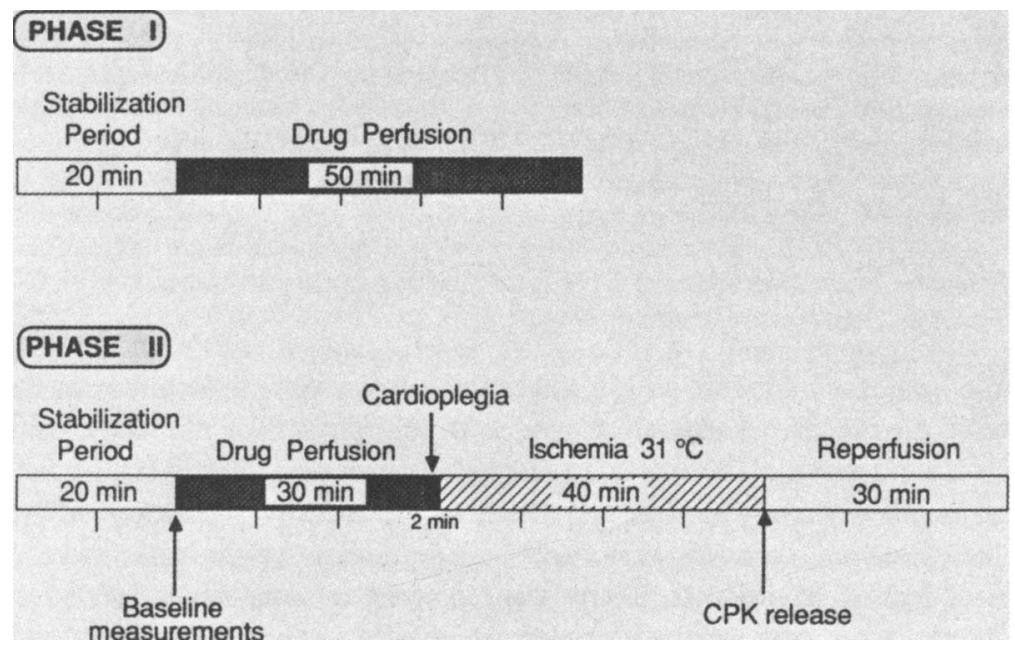

Fig. 1. Study protocol.

myocardial ultrastructures. ${ }^{18,19}$ However, the effect of the drug on the functional recovery of the ischemic heart is yet unclear. In one set of experiments, survival was better among dogs pretreated with a high dose of aprotinin, ${ }^{18}$ whereas in another study isolated canine hearts treated with aprotinin had significantly poorer functional recovery of the left ventricle after ischemia and reperfusion. ${ }^{19}$

The present study had two aims: (1) to observe the direct effect of increasing doses of aprotinin on the normally perfused hearts and (2) to investigate the effect of high-dose aprotinin (in concentrations used clinically) on the functional recovery of the ischemic heart. A modified Langendorff isolated rat heart model was used.

\section{Materials and methods}

Male Wistar rats ( 320 to $450 \mathrm{gm}$ ) were anesthetized with diethyl ether. Each rat's heart was rapidly excised, immersed in ice-cold heparinized saline, and mounted on the stainless steel cannula of a modified Langendorff perfusion apparatus. Retrograde aortic perfusion was initiated at a perfusion pressure of 80 $\mathrm{mm} \mathrm{Hg}$ with an oxygenated modified Krebs-Henseleit buffer solution having the following composition (in millimoles per liter): $\mathrm{NaCl} 118 ; \mathrm{KCl} 4.7 ; \mathrm{CaCl} 2.0 ; \mathrm{MgSO}_{4} \cdot 7 \mathrm{H}_{2} \mathrm{O}$ 1.2; $\mathrm{KH}_{2} \mathrm{PO}_{4}$ 1.2; glucose 11.1; $\mathrm{NaHCO}_{3} 25$. The perfusate was bubbled continuously with $95 \%$ oxygen and $5 \%$ carbon dioxide and a $\mathrm{pH}$ of 7.4 to 7.5 was maintained. Oxygen and carbon dioxide tensions in the perfusion solution were 450 to $550 \mathrm{~mm}$ $\mathrm{Hg}$ and 25 to $30 \mathrm{~mm} \mathrm{Hg}$, respectively. The heart temperature was monitored by a thermistor implanted in the right ventricular wall. It was carefully maintained at $37^{\circ} \mathrm{C}$ or $31^{\circ} \mathrm{C}$ (at ischemia) by means of water jacketing of the perfusate reservoir and the isolated heart. The right atrium was removed and the heart was paced to 300 beats/min at 4 volts with an external pacemaker (Devices Limited, Implants Division, type E4162, Welwyn Garden City, Herts, Great Britain), ensuring identical heart rates for all the hearts. A water-filled latex balloon was placed in the left ventricular cavity through a small incision in the left atrium and was connected to a PI 32284 pressure transducer (Mennen Medical, Inc., Clarence, N.Y.). The balloon was tied and inflated to a volume that produced $0 \mathrm{~mm} \mathrm{Hg}$ diastolic pressure. Zero calibration of the pressure transducer was checked throughout the experiment. Left ventricular pressure, time to peak systolic pressure, relaxation time, the first derivative of the rise and fall of left ventricular pressure $( \pm \mathrm{dP} /$ $\left.\mathrm{dT}_{\max }\right)$, and coronary flow were measured. The various parameters checked were continuously recorded and measurements were taken at 10-minute intervals.

All animals received humane care as described by the "Principles of Laboratory Animal Care" formulated by the National Society for Medical Research and the "Guide for the Care and Use of Laboratory Animals" prepared by the National Academy of Sciences and published by the National Institutes of Health (NIH publication No. 86-23, revised 1985).

Protocol. Fifty rats were randomly divided into five subgroups of 10 animals each. Three subgroups were studied under phase I protocol, which was designed to check the direct effect of aprotinin on normally perfused hearts (Fig. 1, phase I). Control measurements were recorded after a 20 -minute period of stabilization. Thereafter, hearts were exposed for a 50-minute period to Krebs-Henseleit solution containing either a high or low concentration of aprotinin or no aprotinin $\left(1 \cdot 10^{6} \mathrm{KIU} / \mathrm{L}\right.$, $1 \cdot 10^{5} \mathrm{KIU} / \mathrm{L}$, or $0 \mathrm{KIU} / \mathrm{L}$, respectively), administered with an infusion pump.

The other two subgroups were studied under phase II protocol, which was designed to assess the effect of aprotinin on ischemic hearts (Fig. 1, phase II). After a 20-minute period of stabilization, each heart was perfused for 30 minutes by switching to another reservoir containing either aprotinin $1 \cdot 10^{6}$ $\mathrm{KIU} / \mathrm{L}$ or saline solution (the control group), immersed in Krebs-Henseleit solution. Warm cardioplegia was initiated for 2 minutes $\left(37^{\circ} \mathrm{C}\right.$, perfusion pressure $60 \mathrm{~mm} \mathrm{Hg}$, potassium chloride $16 \mathrm{mEq} / \mathrm{L}$ in Krebs-Henseleit solution with or without aprotinin), and then a 40-minute period of global ischemia at $31^{\circ} \mathrm{C}$ was applied to the arrested heart. Ischemic contracture was measured. Creatine kinase (CK) activity was measured 
Table I. Entering parameters to phase I

\begin{tabular}{|c|c|c|c|}
\hline & $\begin{array}{l}\text { Control } \\
(\mathrm{n}=10)\end{array}$ & $\begin{array}{l}\text { Low-dose aprotinin } \\
(\mathrm{n}=10)\end{array}$ & $\begin{array}{l}\text { High-dose aprotinin } \\
(\mathrm{n}=10)\end{array}$ \\
\hline Body weight (gm) & $338.9 \pm 8.0$ & $335 \pm 9.2$ & $330.8 \pm 5.5$ \\
\hline Dry heart weight $(\mathrm{gm})$ & $0.2 \pm 0.006$ & $0.19 \pm 0.003$ & $0.2 \pm 0.005$ \\
\hline Contraction amplitude $(\mathrm{mm} \mathrm{Hg})$ & $117 \pm 7.3$ & $97.8 \pm 8.2$ & $97.8 \pm 7.6$ \\
\hline Time to peak systole $(\mathrm{msec})$ & $51.1 \pm 1.8$ & $50.8 \pm 1.6$ & $51.1 \pm 1.6$ \\
\hline Relaxation time (msec) & $70.2 \pm 1.36$ & $72.4 \pm 2.97$ & $71.1 \pm 2.91$ \\
\hline$+\mathrm{dP} / \mathrm{dT}_{\max }(\mathrm{mm} \mathrm{Hg} / \mathrm{msec})$ & $3881 \pm 206$ & $3262 \pm 324$ & $3135 \pm 208$ \\
\hline$-\mathrm{dP} / \mathrm{dT}_{\max }(\mathrm{mm} \mathrm{Hg} / \mathrm{msec})$ & $2675 \pm 163$ & $2150 \pm 204.4$ & $2125 \pm 129$ \\
\hline Coronary flow $(\mathrm{ml} / \mathrm{min})$ & $25.1 \pm 1.8$ & $21.4 \pm 2.1$ & $20.4 \pm 2.1$ \\
\hline Coronary flow $/ \mathrm{wt} .(\mathrm{ml} / \mathrm{min} \cdot \mathrm{gm})$ & $115.5 \pm 5.4$ & $100 \pm 7.0$ & $106.0 \pm 11.3$ \\
\hline
\end{tabular}

spectrophotometrically in the effluent at the first minute of reperfusion after ischemia. ${ }^{20}$ Left ventricular function was measured every 10 minutes during the 30 -minute reperfusion period. Perfusate afferent and efferent gases were measured after 20 minutes of stabilization, 1 minute before cardioplegia, and at the end of reperfusion. Samples were withdrawn from the Langendorff perfusion apparatus and from the right ventricle with a tiny polyethylene catheter inserted through a pulmonary artery incision.

Oxygen consumption $\left(\mathrm{VO}_{2}\right)$ was calculated by the following formula ${ }^{21}$ :

$$
\begin{gathered}
\mathrm{VO}_{2}(\mathrm{mmol} / \mathrm{hr} / \mathrm{gm})= \\
\frac{\text { Arteriovenous } \mathrm{O}_{2} \text { tension }(\mathrm{mm} \mathrm{Hg})}{760(\mathrm{~mm} \mathrm{Hg})} \times \\
\frac{\text { Solubility of } \mathrm{O}_{2} \text { at } 37^{\circ} \mathrm{C}\left(\mathrm{ml} / \mathrm{ml} \mathrm{H}_{2} \mathrm{O}\right)}{22.4(\mathrm{ml} / \mathrm{mmol})} \times \\
\frac{\text { Coronary flow }(\mathrm{ml} / \mathrm{hr})}{\text { Dry weight of heart }(\mathrm{gm})}
\end{gathered}
$$

Finally the hearts were dried at $90^{\circ} \mathrm{C}$ for 24 hours to achieve a constant weight. Wet/dry weight ratio was calculated for each heart to evaluate the water content. Throughout the study, experiments were alternated between the control and the experimental limbs to avoid bias or differences in results.

Presentation of results. Results are presented as mean \pm standard error. So that differences in baseline values could be avoided, the value of the first 20 minutes of contraction of each heart was used as that heart's individual control. All control values of left ventricular function and coronary effluent were considered as $100 \%$. Coronary effluent was normalized to grams of dry heart weight. Data were analyzed by Student's paired or unpaired $t$ test, with $p<0.05$ accepted as showing statistical significance. Two-way analysis of variance (ANOVA) for drug and time effect was calculated for the parameters before and after ischemia.

\section{Results}

Phase I. All entering parameters taken after $20 \mathrm{~min}$ utes of stabilization were statistically similar for the three

\begin{tabular}{|c|c|c|}
\hline & $\begin{array}{l}\text { Control } \\
(\mathrm{n}=10)\end{array}$ & $\begin{array}{l}\text { Aprotinin } \\
(\mathrm{n}=10)\end{array}$ \\
\hline Body weight (gm) & $359.4 \pm 10.7$ & $367.1 \pm 8.9$ \\
\hline Dry heart weight $(\mathrm{gm})$ & $0.2 \pm 0.006$ & $0.19 \pm 0.007$ \\
\hline $\begin{array}{l}\text { Contraction amplitude } \\
\quad(\mathrm{mm} \mathrm{Hg})\end{array}$ & $116 \pm 8.4$ & $106.9 \pm 8.5$ \\
\hline $\begin{array}{l}\text { Time to peak systole } \\
\text { (msec) }\end{array}$ & $55.6 \pm 1.1$ & $54.8 \pm 1.3$ \\
\hline Relaxation time (msec) & $77.2 \pm 1.3$ & $75.2 \pm 2.65$ \\
\hline $\begin{array}{c}+\mathrm{dP} / \mathrm{dT}_{\max }(\mathrm{mm} \\
\mathrm{Hg} / \mathrm{msec})\end{array}$ & $3554 \pm 205$ & $3337 \pm 240$ \\
\hline $\begin{array}{c}-\mathrm{dP} / \mathrm{dT}_{\max }(\mathrm{mm} \\
\mathrm{Hg} / \mathrm{msec})\end{array}$ & $2597 \pm 185$ & $2441 \pm 212$ \\
\hline Coronary flow $(\mathrm{ml} / \mathrm{min})$ & $16.7 \pm 1.46$ & $17.7 \pm 1.46$ \\
\hline $\begin{array}{l}\text { Coronary flow/weight } \\
(\mathrm{ml} / \mathrm{min} \cdot \mathrm{gm})\end{array}$ & $89.6 \pm 6.4$ & $94.4 \pm 6.4$ \\
\hline $\begin{array}{l}\text { Oxygen consumption } \\
(\mathrm{mmol} / \mathrm{hr} \text { per gram })\end{array}$ & $2.52 \pm 0.21$ & $2.77 \pm 0.2$ \\
\hline
\end{tabular}
groups of hearts (Table I). No statistically significant differences in contraction amplitude and in $\pm \mathrm{dP} / \mathrm{dT}_{\max }$ were found among the three groups of hearts-those per-
Table II. Entering parameters to phase II

fused with a high dose of aprotinin, those treated with a lower dose, and the control group, not perfused with the drug (Fig. 2, $A$ to $C$ ). Aprotinin did not have any significant effect on the coronary flow (Fig. 2, D) or on the wet/dry weight ratio of the hearts $(5.81 \pm 0.16,5.6 \pm$ 0.13 , and $5.3 \pm 0.12$, respectively).

Phase II. All entering parameters to phase II (Table II) taken after 20 minutes of stabilization were statistically similar for the hearts treated with aprotinin and the control group.

Hemodynamic measurements. According to two-way ANOVA, no statistically significant differences were found in contraction amplitude curves between hearts treated with aprotinin and the control group before and after ischemia (Fig. 3).

Like phase I results, in phase II aprotinin had no effect on left ventricular performance before ischemia, neither on contractility $\left(+\mathrm{dP} / \mathrm{dT}_{\max }\right)$ (Fig. $4 A$ ) nor on relaxation $\left(-\mathrm{dP} / \mathrm{dT}_{\max }\right.$ ) (Fig. $\left.4, B\right)$. However, after 40 minutes of 

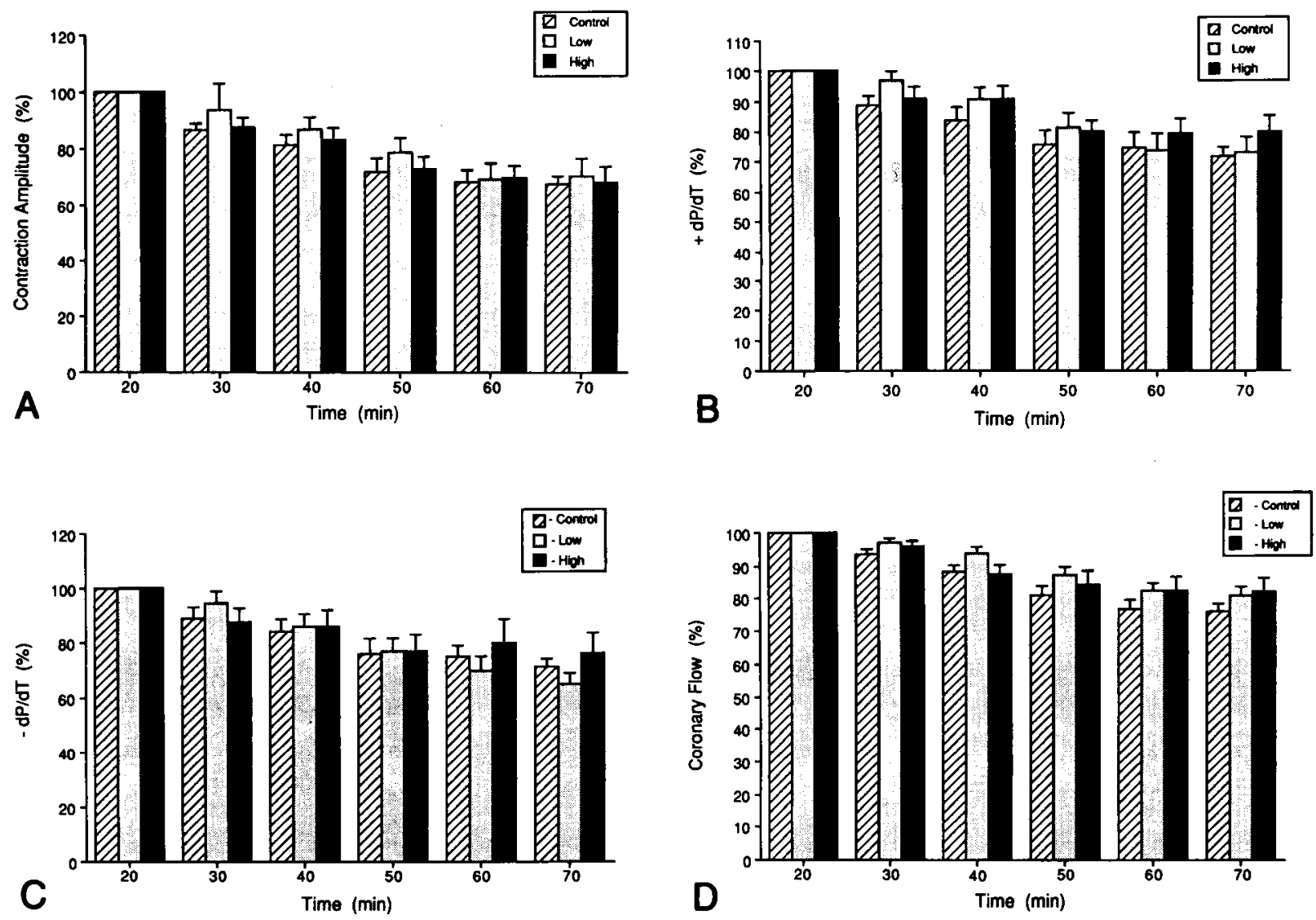

Fig. 2. Phase I measurements of contraction amplitude (A), first derivative of rise (B) and fall (C) of left ventricular pressure, and coronary flow (D). Results are represented as each heart's percentage of baseline measurements taken after 20 minutes of stabilization. Low aprotinin concentration $=10^{5} \mathrm{KIU} / \mathrm{L}$; high aprotinin concentration $=10^{6}$ $\mathrm{KIU} / \mathrm{L}$; control = normal saline solution.

warm ischemia, recovery was significantly better in hearts treated with aprotinin than in control hearts, and during the reperfusion period their contractility and relaxation were better. ANOVA calculated for drug effect was 0.011 for both (Fig. 4).

Ischemic contracture was similar in the two groups $(21.6 \pm 18.4 \mathrm{~mm} \mathrm{Hg}$ in the aprotinin group and $22.4 \pm 26.3 \mathrm{~mm} \mathrm{Hg}$ in the control group).

Postischemic data indicate that both contraction (time from end-diastolic pressure to peak systolic pressure) and relaxation (time from peak systolic pressure to baseline) were significantly shorter in the aprotinin-treated hearts (ANOVA, $p=0.045$ and $p=0.005$, respectively). After 30 minutes of reperfusion, average time from left ventricular end-diastolic pressure to peak systolic pressure was $46.4 \pm 1.4 \mathrm{msec}$ in the aprotinin group and $50.0 \pm 1.6 \mathrm{msec}$ in the control group $(p=0.051)$. Time for relaxation was $66.0 \pm 2.3 \mathrm{msec}$ versus $76.0 \pm 2.7$ msec, respectively $(p<0.01)$. Diastole, therefore, was altogether $18 \%$ longer in hearts treated with aprotinin during the reperfusion period.

Coronary flow. Postischemic measurements showed significantly higher coronary effluent in the aprotinin group (ANOVA, $p<0.04$; Fig. 5). After 30 minutes of reperfusion, coronary effluent was $83.7 \% \pm 8.2 \%$ of baseline flow measurements in the aprotinin group and only $59.1 \% \pm 6.6 \%$ in the untreated group $(p<0.025)$.

Oxygen consumption. Oxygen consumption declined spontaneously in both groups of hearts before ischemia. Before ischemia no statistically significant differences were noted between the groups $(2.04 \pm 0.23 \mathrm{mmol} / \mathrm{hr}$ per gram in the aprotinin group versus $2.26 \pm 0.16$ $\mathrm{mmol} / \mathrm{hr}$ per gram in the control group). Ischemia had no influence on oxygen consumption in the aprotinin group $(2.04 \pm 0.23 \mathrm{mmol} / \mathrm{hr}$ per gram before ischemia and $2.04 \pm 0.24 \mathrm{mmol} / \mathrm{hr}$ per gram on reperfusion). Howev- 


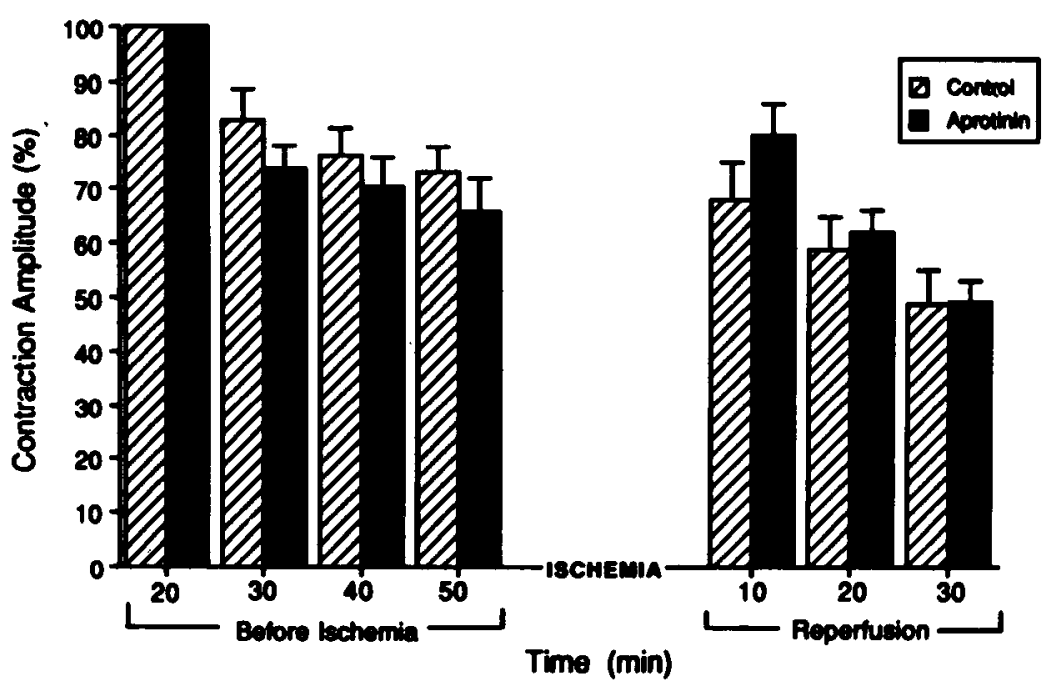

Fig. 3. Comparison between hearts treated with high-dose aprotinin and the control group showed no differences between the groups before and after ischemia. Contraction amplitude is represented as each heart's percentage of baseline measurement taken after 20 minutes of stabilization.

$\mathrm{er}$, in the control group, prolonged ischemia decreased the oxygen consumption dramatically, from $2.26 \pm 0.16$ $\mathrm{mmol} / \mathrm{hr}$ per gram to $1.5 \pm 0.22 \mathrm{mmol} / \mathrm{hr}$ per gram; $p=0.006$ (Fig. 6).

$C K$. Multiplied by flow rate at the first minute of reperfusion, $C K$ excretion by aprotinin-treated hearts was significantly less than that of the control group (892 \pm $85.3 \mathrm{mU} / \mathrm{min}$ versus $1244 \pm 111 \mathrm{mU} / \mathrm{min}$, respectively; $p<0.01$ ) (Fig. 7).

Weight ratios. No differences in wet/dry heart weight ratio were observed between the aprotinin and the control groups ( $5.76 \pm 0.22$ versus $5.8 \pm 0.09$, respectively).

\section{Discussion}

Several studies have now confirmed the observation made by Bistrup and others ${ }^{15-17}$ that high-dose aprotinin reduces bleeding after cardiac operations by approximately $50 \%$. As a result, the use of the drug has increased.

It was crucial to determine the effect of aprotinin on the myocardium before and after prolonged cardioplegic ischemia followed by reperfusion. Consequently, this study was carried out.

Primum non nocere. The lack of toxicity of the drug while perfusing a normal, nonischemic heart was evidenced through phase I of the study. No differences in myocardial performance were observed between the two groups treated with high and low concentrations of aprotinin and between the control group. The same results were also evident during the preischemic period in phase II of the study. These results offer additional support for the safety of the drug when used in nonischemic hearts.

Phase II was plotted to investigate the effect of aprotinin on the ischemic heart. During this phase only one concentration of the drug was used. Because relatively high doses of aprotinin are required to reduce bleeding in clinical situations, we decided to use the higher dose, equivalent to concentrations used in the priming solution in our department $\left(10^{6} \mathrm{KIU} / \mathrm{L}\right)$.

Aprotinin exerts various effects on tissue when used in a tissue culture model at extremely high concentrations (up to $10^{7} \mathrm{KIU} / \mathrm{L}$ ). ${ }^{22,23} \mathrm{The}$ effect of aprotinin on organ preservation-liver, kidney, and lung-has also been studied. ${ }^{24-29}$ This proteinase inhibitor was shown to protect dog myocardium against ischemic injury in terms of diminished area of infarction after coronary artery ligation. ${ }^{30}$ Sunamory and associates ${ }^{18}$ demonstrated that systemic pretreatment with aprotinin during cardiopulmonary bypass at a concentration of $20,000 \mathrm{KIU} / \mathrm{kg}$ was effective in reducing lysosomal enzyme activation and in maintaining canine myocardial viability.

In a recent experimental study of that group, aprotinin was used in the cardioplegic solution at concentrations of $150 \mathrm{KIU} / \mathrm{ml} .{ }^{19}$ Release of lysosomal enzyme into the coronary sinus was suppressed, myocardial adenosine triphosphate and diphosphate levels tended to be higher, and total adenine nucleotides were significantly better preserved during reperfusion in aprotinin-treated hearts than in the control group. Less injury to myocardial ultrastructure was observed in the aprotinin-treated group. However, hearts in the control group showed sig- 

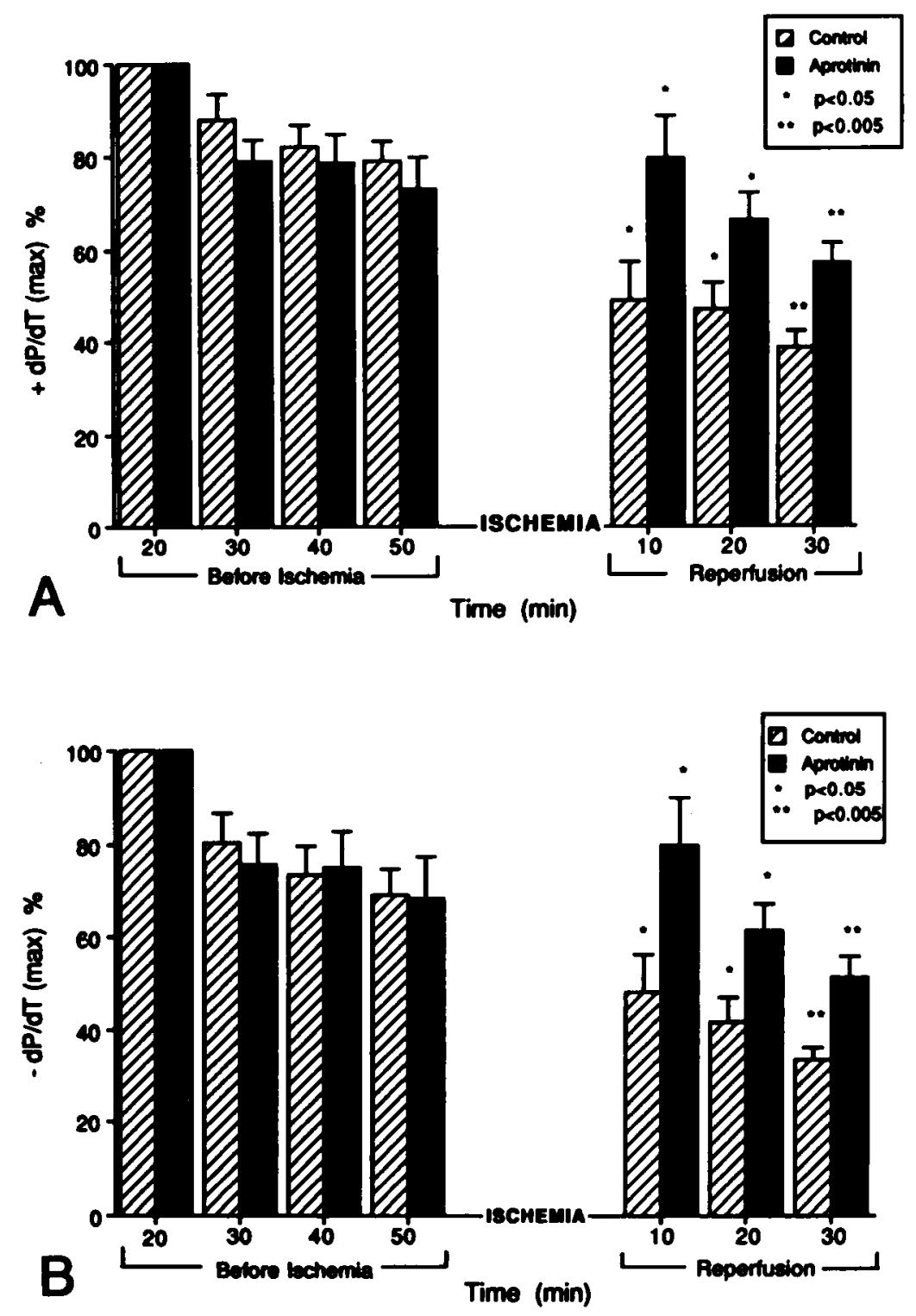

Fig. 4. At reperfusion, hearts treated with aprotinin had a significantly better rise (A) and fall (B) of the first derivative of left ventricular pressures. ANOVA for drug effect was 0.011 . Results are represented as each heart's percentage of baseline measurements taken after 20 minutes of stabilization.

nificantly better contractility after 60 minutes of reperfusion than did canine hearts treated with aprotinin. Hjelms and colleagues ${ }^{31}$ showed that aprotinin did not add any protective effect to cold cardioplegia during coronary artery bypass operations.

In the present study aprotinin was infused into the coronary tree for 30 minutes before ischemia. That period of time allowed an adequate exposure of the myocardial tissues to the drug. A further exposure to aprotinin was achieved during a 2-minute period of warm cardioplegia. The temperature during ischemia $\left(31^{\circ} \mathrm{C}\right)$ was chosen because previous results illustrated that there was a sharp decline in protection when the temperature rose above $30^{\circ} \mathrm{C}^{32}$

Our results clearly portray that hearts pretreated with aprotinin had better recovery of myocardial function after ischemia than hearts not treated with the drug, as evidenced by significantly better contractility $( \pm \mathrm{dP} /$ 


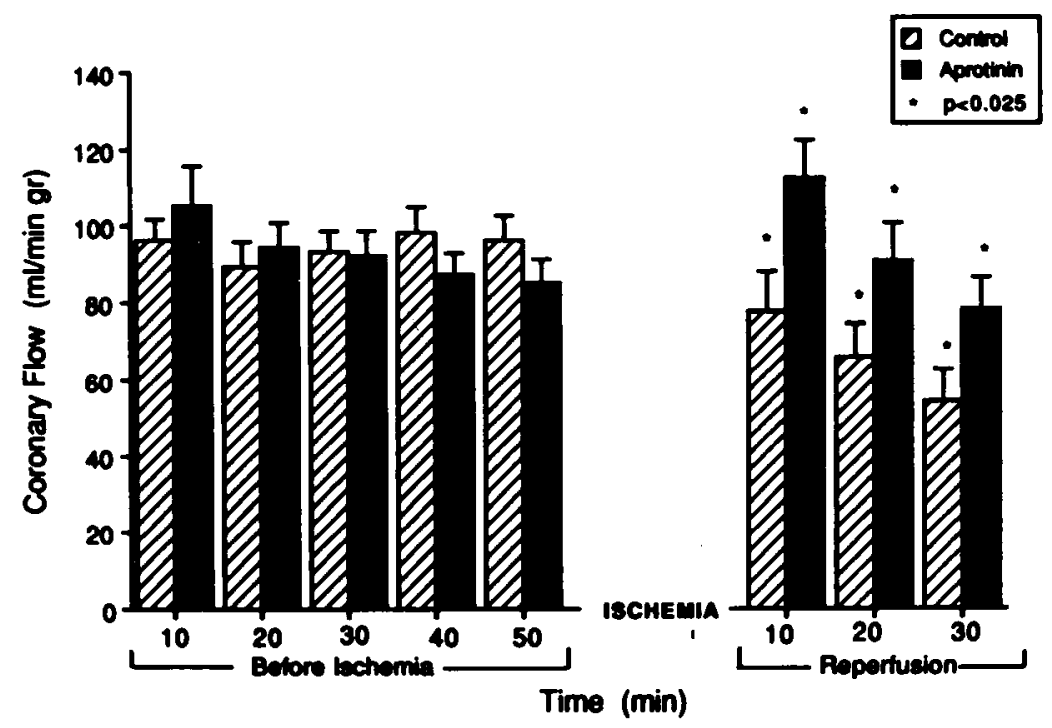

Fig. 5. Aprotinin-treated hearts had a higher coronary flow during reperfusion than the control group. ANOVA for drug effect was less than 0.04 .

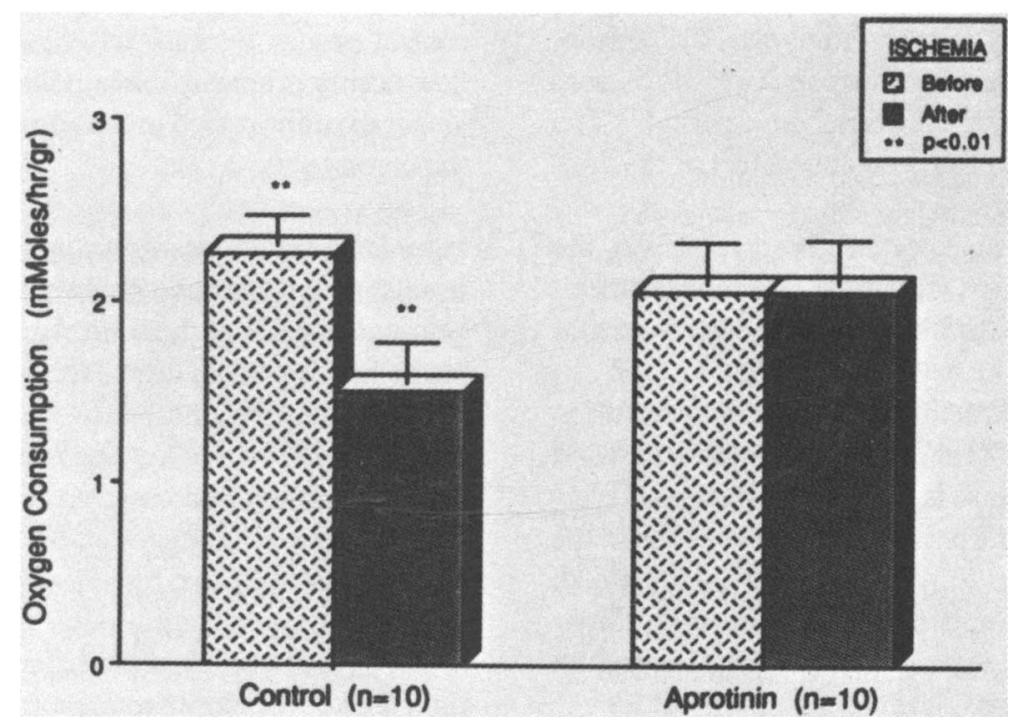

Fig. 6. Oxygen consumption in the control group decreased significantly after ischemia. Ischemia had no effect on aprotinin-treated hearts. Samples were taken 1 minute before cardioplegia and at the end of the reperfusion period.

$\left.d T_{\max }\right)$. CK levels of the efferent fluid at the first minute of reperfusion were significantly lower in the aprotinintreated hearts, suggesting less myocardial necrosis and damage after the prolonged ischemia.

These results are at variance with recent publications that showed no added protection of the drug to cold cardioplegia during coronary bypass grafting in one clinical study $^{31}$ and even a depressed recovery of myocardial function in another experimental study. ${ }^{19}$ Previous stud- ies failed to demonstrate lower CK levels in aprotinintreated groups, although this important parameter, reliably reflecting myocardial tissue damage, was checked constantly. ${ }^{18,19,31}$

The improved recovery observed in the present study and the significantly lower CK levels might be the consequence of a longer preischemic exposure to a significantly higher (up to twentyfold) dosage of the drug in our study. ${ }^{31}$ It seems likely that an adequate period of expo- 


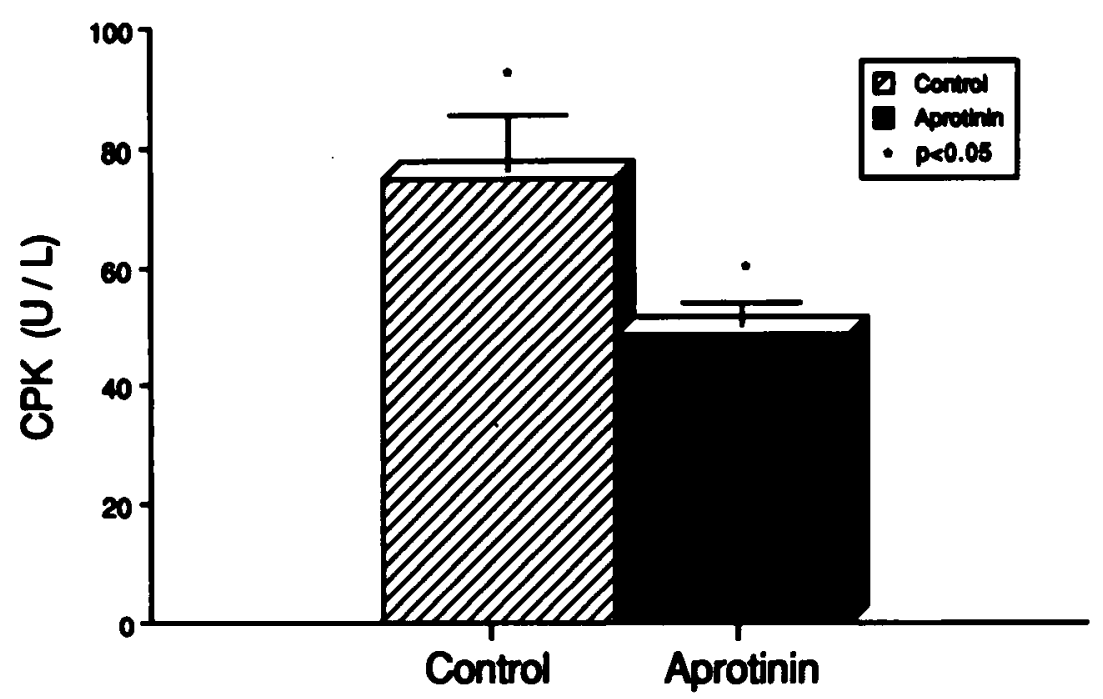

Fig. 7. Effluent CK levels as measured at the first minute of reperfusion.

sure to the drug is necessary. Duration of cardioplegia per se might not be long enough. It is important, in that view, to notice that in the only previous study that did demonstrate improved mechanical performance at reperfusion, aprotinin was given during the preischemic period. ${ }^{18}$ The same study revealed that the protective effect of the drug was dose dependent.

An interesting and unexpected observation was the increase in the contraction amplitude, which was detected in the aprotinin-treated hearts after 10 minutes of reperfusion (Fig. 3).

A decrease in the contraction amplitude on reperfusion measured in the control group is a daily observation, and the pathophysiologic cause is well established. ${ }^{1-4}$ Nevertheless, the increase in the postischemic contraction in the aprotinin-treated group is not completely understood. One possible explanation is an increase in intracellular calcium, accumulated during the ischemic period in aprotinin-treated hearts. ${ }^{19}$

Usually, such intracellular accumulation of calcium in combination with low adenosine triphosphate levels is harmful and may cause a destruction of intracellular organelles and a further decrease in adenosine triphosphate levels. ${ }^{1,2,7-9}$ However, when combined with wellpreserved and normally performing mitochondria and relatively high postischemic adenosine triphosphate lev$\mathrm{els},{ }^{18,19}$ this increase in calcium concentration in aprotinin-treated hearts may result in a better contractility and contraction amplitude.

In hearts treated with the drug, postischemic coronary flow, measured on reperfusion, was significantly higher.
During reperfusion, the hearts had a significantly shorter systolic contraction and relaxation than hearts in the control group. Because left ventricular coronary blood flow occurs primarily during diastole, the resultant $18 \%$ longer diastolic period in the aprotinin group might affect the coronary flow rate.

The coronary circulation is governed primarily by autoregulating mechanisms: increase in oxygen demand results in an increased coronary flow rate. Whereas oxygen consumption at the control group declined during the postischemic period, hearts treated with aprotinin maintained a constant and relatively high oxygen consumption. This reflects a better postischemic myocardial recovery and viability. Decreased viable myocardial mass in the control group was suggested by higher CK levels in the postischemic effluent, by worsened contractility, and by decreased oxygen consumption. The spontaneous decline in the oxygen consumption before ischemia in the aprotinin group was more pronounced than the decline in the control group, and we do not have a satisfactory explanation for this observation.

Our study did not attempt to elucidate the means by which aprotinin protected the heart. However, the use of blood-free medium in the isolated heart model, despite some clinical limitations, appears to be advantageous. Inhibition of the circulating kinins by aprotinin ${ }^{30}$ can be ruled out by the use of this model. Therefore the following conclusion can be drawn from this study: The protective effect of aprotinin might be induced by myocardial protease inhibition and by protecting myocardial membranes from these protease attacks, ${ }^{19,22,23}$ and not only 
by preventing the lysosomal liberation of polymorphonuclear leukocytes and reperfusion damage to the myocardium, and by other antichemotactic and antiinflammatory properties of this drug. ${ }^{30,33}$

Follow-up studies in the Langendorff mode, as well as in other experimental models, in an attempt to further elucidate the mechanisms by which this drug acts to protect the ischemic reperfused myocardium should be considered.

In summary, the effect of high-dose aprotinin treatment on ischemic and nonischemic myocardium was studied in an isolated rat heart model. The drug did not affect myocardial performance before ischemia.

On reperfusion, hearts treated with aprotinin had a significantly better recovery than the control group, as reflected by an increase in contractility, an increase in coronary flow, an unchanged oxygen consumption, and significantly lower $\mathrm{CK}$ levels.

All represented data were statistically analyzed by our consultant statistician, Mrs. Yael Villa, MSc., School of Mathematics, Tel-Aviv University.

\section{REFERENCES}

1. Hearse DJ, Braimbridge MV, Jynge P. Ischemia and reperfusion: the progression and prevention of tissue injury. In: Protection of the ischemic myocardium: cardioplegia. 1st ed. New York: Raven Press, 1981:21-49.

2. Hearse DJ. Reperfusion of the ischemic myocardium. J Mol Cell Cardiol 1977;9:605-16.

3. Jennings RS, Sommers HM, Smith GA, Flack HA, Linn $\mathrm{H}$. Myocardial necrosis induced by temporary occlusion of a coronary artery in the dog. Arch Pathol 1960;70:8294.

4. Engelman RM, Chandra R, Bauman FG, Goldman RA. Myocardial reperfusion: a cause of ischemic injury during cardiopulmonary bypass. Surgery 1976;80:266-76.

5. Hearse DJ, Humphrey SM, Chain EB. Abrupt reoxygenation of the anoxic potassium arrested perfused rat hearts: a study of myocardial enzyme release. J Mol Cell Cardiol 1973;5:395-407.

6. Hearse DJ, Humphrey SM, Nayler WG, Slade A, Boder D. Ultrastructural damage associated with reoxygenation of the anoxic myocardium. J Mol Cell Cardiol 1975;7:31524.

7. Hearse DJ, Stuart MH, Bullock GR. The oxygen paradox and the calcium paradox: Two facets of the same problem? J Mol Cell Cardiol 1978;10:641-68.

8. Zimmerman ANE, Hulsmann WC. Paradoxical influence of calcium ions on the permeability of the cell membranes in the isolated rat heart. Nature 1966;212:646-7.

9. Zimmerman ANE, Daems W, Hulsmann WC, Synder J, Wisse E, Durrer D. Morphological changes of heart mus- cle caused by successive perfusion with calcium free and calcium containing solutions (calcium paradox). Cardiovasc $R$ es 1967;1:201-9.

10. Fox AC, Hoffstein S, Weissmann G. Lysosomal mechanisms in production of tissue damage during myocardial ischemia and the effects of treatment with steroids. Am Heart J 1976; 91:394-7.

11. Hoffstein S, Weissmann G, Fox AC. Lysosomes in myocardial infarction: studies by means of cytochemistry and subcellular fractination, with observations on the effects methylprednisolone. Circulation 1976;53:34-40.

12. Ricciutti MA. Lysosomes and myocardial cellular injury. Am J Cardiol 1972;2:277-92.

13. Weglicki WB, Owens K, Ruth RC, Sonnenblick EH. Activity of endogenous myocardial lipases during incubation at acid pH. Cardiovasc Res 1974;8:237-42.

14. Welman E, Peters TJ. Enhanced lysosome fragility in the anoxic perfused guinea pig heart: effects of glucose and mannitol. J Mol Cell Cardiol 1977;9:101-20.

15. Bidstrup BP, Royston D, Sapsford RN, Taylor KM. Reduction in blood loss and blood use after cardiopulmonary bypass with high-dose aprotinin (Trasylol). J THORAC Cardiovasc SuRg 1989;97:364-72.

16. Royston D, Bidstrup BP, Taylor KM, Sapsford RN. Effect of aprotinin on need for blood transfusion after repeat open heart surgery. Lancet 1987;2:1289-91.

17. Blauhut B, Gross C, Necek S, et al. Effects of highdose aprotinin on blood loss, platelet function, fibrinolysis, complement, and renal function after cardiopulmonary bypass. J THORAC CARDIOVASC SURG 1991;101:95867.

18. Sunamori M, Innami R, Amano J, Suzuki A, Harrison CE. Role of protease inhibition in myocardial preservation in prolonged hypothermic cardioplegia followed by reperfusion. J THORAC CardiovasC SURG 1988;96:31420.

19. Sunamori M, Sultan I, Suzuki A. Effect of aprotinin to improve myocardial viability in myocardial preservation followed by reperfusion. Ann Thorac Surg 1991;52: 971-8.

20. CBR program Boehringer for automated analysis. J Clin Chem Clin Biochem 1977;15:249-50.

21. Neely JR, Liebermeister H, Battersby EJ, Morgan HE. Effects of pressure development on oxygen consumption by isolated rat hearts. Am J Physiol 1967;212:804-14.

22. Davis H, Gascho C, Keirnan JA. Action of aprotinin on the survival of adult cerebellar neurons in organ culture. Acta Neuropathol (Berlin) 1975;32:359-62.

23. Davis H, Gascho C, Keirnan JA. Effects of aprotinin on organ cultures of the rat's kidney. In Vitro 1976;12:192-7.

24. Lie TS, Seger R, Hong S, et al. Protective effect of aprotinin on ischemic hepatocellular damage. Transplantation. 1989;48:396-9.

25. Takei Y, Marzi I, Kauffman FC, et al. Increase in survival time of liver transplants by protease inhibitors and a calci- 
um channel blocker, nifedipine. Transplantation 1990; 50:14-20.

26. Oldhafer KJ, Schattler W, Hauss J, Pichlmayr R. Treatment of preservation/reperfusion liver injury by the protease inhibitor aprotinin after cold ischemic storage. Transplant Proc 1991;23:2380-1.

27. Godfrey AM, Salman JR. Trasylol (Aprotinin) and kidney preservation. Transplantation. 1978;25:167-8.

28. Guthrie R, Rizzi GTA, McCabe RE. Experimental study of the effect of a proteinase inhibitor (Trasylol) on organ preservation. Am J Surg 1966;1 12:835-8.

29. Hoyer J, Garbe L, Delpierre S, Prieur A, Macquart-Moulin G, Noirclerc M. Functional evaluation of the transplanted lung after long-term preservation. Respiration 1980;39:323-32.
30. Diaz PE, Fishbein MC, Davis MA, Ashkenazi J, Maroko P. Effect of the kalikrein inhibitor aprotinin on cardial ischemic injury after coronary occlusion in the dog. Am J Cardiol 1977;40:541-9.

31. Hjelms E, Waldorff S, Steiness E, Bergstan O. Aprotinin does not add protective effect to cold cardioplegia during coronary artery bypass surgery. Scand J Thorac Cardiovasc Surg 1986;20:11-3.

32. Hearse DJ, Stewart DA, Braimbridge MV. Cellular protection during myocardial ischemia. Circulation 1976; 54:193-202.

33. Hartman JR, Robinson JA, Gunnar RM. Chemotactic activity in the coronary sinus after experimental myocardial infarction: effects of pharmacologic interventions on ischemic injury. Am J Cardiol 1977;40:550-5. 